\title{
ASTRONOMÍA CULTURAL DE LOS GEOGLIFOS ANDINOS: UN ENSAYO SOBRE LOS ANTIGUOS TARAPAQUEÑOS, NORTE DE CHILE
}

\author{
THE CULTURAL ASTRONOMY OF ANDEAN GEOGLYPHS: A CASE STUDY \\ OF ANCIENT TARAPAQUEÑOS, NORTHERN CHILE
}

\author{
Persis B. Clarkson ${ }^{*}$ y Luis Briones Morales ${ }^{* *}$
}

\begin{abstract}
La incorporación de la astronomía en los ritos y sitios en la región Andina está bien documentada en las épocas de pre y postcontacto. En el Norte de Chile, a una escasa arquitectura monumental pretérita y una exigua documentación indígena, han contribuido a su vez a una incompleta información correspondiente al uso de la astronomía por la gente antigua. La abundancia de geoglifos en la región está asociada a los antiguos senderos caravaneros, donde la mayoría de los miles de estos han sido reconocidos. El "Geoglifo Sol", encontrado en el 2008 en la pampa Tamarugal, tiene un diseño complejo y una ubicación sugerente: la forma circular, incluye un antropomorfo y "marcas", todo ubicado en el plano horizontal de la pampa. Además, hay una visión hacia el este interrumpida solo por el Tata Jachura, un volcán inactivo, conocido en las fuentes históricas y modernas como también por los indígenas locales actuales, con manifestaciones rituales. Sin sorprendernos, hay varias correlaciones entre el sol, la luna, y las constelaciones, incluso los equinoccios y los solsticios, con las orientaciones de las marcas y el antropomorfo, por los años 500 y 1500 d.C. La significación de los fenómenos astronómicos y los rasgos terrestres con la mitología regional indicarían los tiempos de construcción y el uso del geoglifo.
\end{abstract}

Palabras claves: geoglifos, Andes, Chile, arqueología, astronomía, simbolismo, arte antiguo.

The incorporation of astronomy into ritual and physical sites is well documented in the Andean region for both the precontact and postcontact periods. In northern Chile, a dearth of ancient architecture and extensive documentation of aboriginal populations has contributed to a corresponding dearth of investigation into the uses of astronomy by the ancient populations. The abundance of geoglyphs (ground drawings) throughout the region is associated with ancient caravan trails. The majority of the tens of thousands of geoglyphs documented in northern Chile fall into recognizable clusters of composition or form. 'Geoglifo Sol', discovered in 2008 in the Pampa Tamarugal, is unusual in composition and location. It is circular, includes an anthropomorph and cairns, and is situated on level terrain. In addition, there is an unobstructed view due west to the Andes and to Cerro Tata Jachura, an inactive volcano with historic and modern documented ritual connotations among the indigenous populations of this region. Not surprisingly, there are several correlations with the cairns and anthropomorph associated with the Geoglifo Sol and alignments to the sun, moon, and specific constellations, including solstices and equinoxes, for the time period of 500-1500 A.D,. The significance of the astronomical phenomena with the terrestrial features and regional mythology further suggests a timeframe of use of the geoglyph.

Key words: geoglyphs, Andes, Chile, archaeology, astronomy, symbolism, art.

\section{Introducción}

Separando las afirmaciones astronómicas de las culturas no literarias y no occidentales, se presenta a los arqueólogos, historiadores, astrónomos entre otros, una apertura fantástica del conocimiento previamente insospechado. Desde la creación en los años 1960 de la disciplina de "astroarqueología", ahora conocida como "astronomía cultural" (Ruggles y Saunders, 1992), hay número tal de descubrimientos increíbles además de ideas muy estrafalarias. Las hipótesis excéntricas vienen de un estado del pensamiento colonialista y occidentalista, pero expresado como ideas científicas y objetivas.
Se reconoce una audacia de estos presuntos estudios científicos que la comprensión, uso e incorporación de la astronomía en la vida cultural era introducida por fuera, con un subtexto que la gente no entendía o no tenía claridad para captar ideas tan sofisticadas. La decadencia más profunda del colonialismo se alcanza con la introducción de lo extraterrestre, porque los humanos no pudieron dar una explicación de su cosmos. Afortunadamente, las explicaciones colonialistas son raras en la literatura científica, pero a la falta de demostrar un contexto razonable entre los parámetros culturales conocidos, podría ser otra forma de imposición occidental, no obstante más sutil.

* Universidad de Winnipeg, Winnipeg, Manitoba, Canadá. Correo electrónico: p.clarkson@ uwinnipeg.ca

** Museo Municipal de Pica, Región de Tarapacá, Chile. Correo electrónico: geoglifo1@ yahoo.es 
El presente estudio trata sobre un ejemplo de cultura material -un geoglifo- entre un contexto ritual y astronómico de los antiguos y modernos habitantes del desierto de Tarapacá en el Norte de Chile (Figuras 1, 2). Hemos considerado la historia tradicional desde los estudios arqueológicos y etnográficos de la región andina del sur de Perú, Bolivia, y las regiones contiguas de Arica-Parinacota y Tarapacá, en el Norte de Chile. Entre este contexto, la trascendencia de las montañas, la historia, la subsistencia, el trueque de larga distancia y la cosmovisión están entretejidos en la vivencia en un mundo por lo demás incierto. Es necesario una aproximación amplia de la geografía y el tiempo: no tenemos ni un fechado específico ni una afiliación cultural para el geoglifo. Este es un problema tanto para el arqueólogo como para el astrónomo porque las interpretaciones pueden ser muy imprecisas. El geoglifo, referido en el futuro como "Geoglifo Sol" -sin la presunción que es una representación del sol-, está en la esfera de la vida andina física, temporal y culturalmente e inserto en una red de senderos que ha servido para movilizar gente, cosas e ideas entre las tierras altas, el desierto y la costa, en el curso de los años.

\section{Montañas e historia}

La importancia de las montañas -conocidas como la llave fundamental en la cultura andina (Bastien, 1978)- en los mitos, símbolos, rituales e historia en la cultura andina está bien documentada (Mishkin, 1949; Reinhard y Sanhueza, 1982; Chacama y Espinoza, 1987; Reinhard, 2002;
Reinhard, 1985), y ha dado énfasis a dicha importancia, como canales para el control del ambiente, el agua y la importancia consecuente de este control en la vida de los agricultores y pastores (Mishkin, 1946:464). La antigüedad de la adoración de las montañas se refleja en un simbolismo muy difundido y compartido en el tiempo y espacio, incluyendo documentaciones del periodo colonial y de sitios arqueológicos de altura (sobre los $5.200 \mathrm{msnm}$ ) como: estructuras, ofrendas rituales y sacrificios humanos. Además, investigaciones etnográficas de la significancia de las montañas en la cultura andina están de acuerdo con el registro colonial y arqueológico. Las montañas dan origen a los grupos étnicos y lugares donde regresan las almas de los muertos; los cementerios antiguos y modernos pueden incluir deliberadamente la posición de los cuerpos con referencia a las montañas (Aldunate y Castro, 1981:80). Según unas fuentes, las mujeres hicieron ofrendas de infantes concebidos por fuerzas naturales, es decir, sin esposos, atribuidos al Tata Jachura (5.252 msnm) para asegurar la lluvia (Reinhard y Sanhueza, 1982).

En la cultura andina existe una asociación de las montañas con las deidades quienes manipulan el ambiente, incluso la lluvia, el agua, relámpagos, granizo, trueno, y meteoros. Según Reinhard (1985), las deidades meteorológicas son más antiguas que la deidad solar-Inti-, porque las deidades del ambiente estaban conectadas directamente con la agricultura, el pastoreo y la vida. La poderosa deidad aymara llamado Tunupa, nombre que significa "espuma del mar", puede tener equivalencia con el dios Inca llamado Viracocha (El Creador). El Tunupa

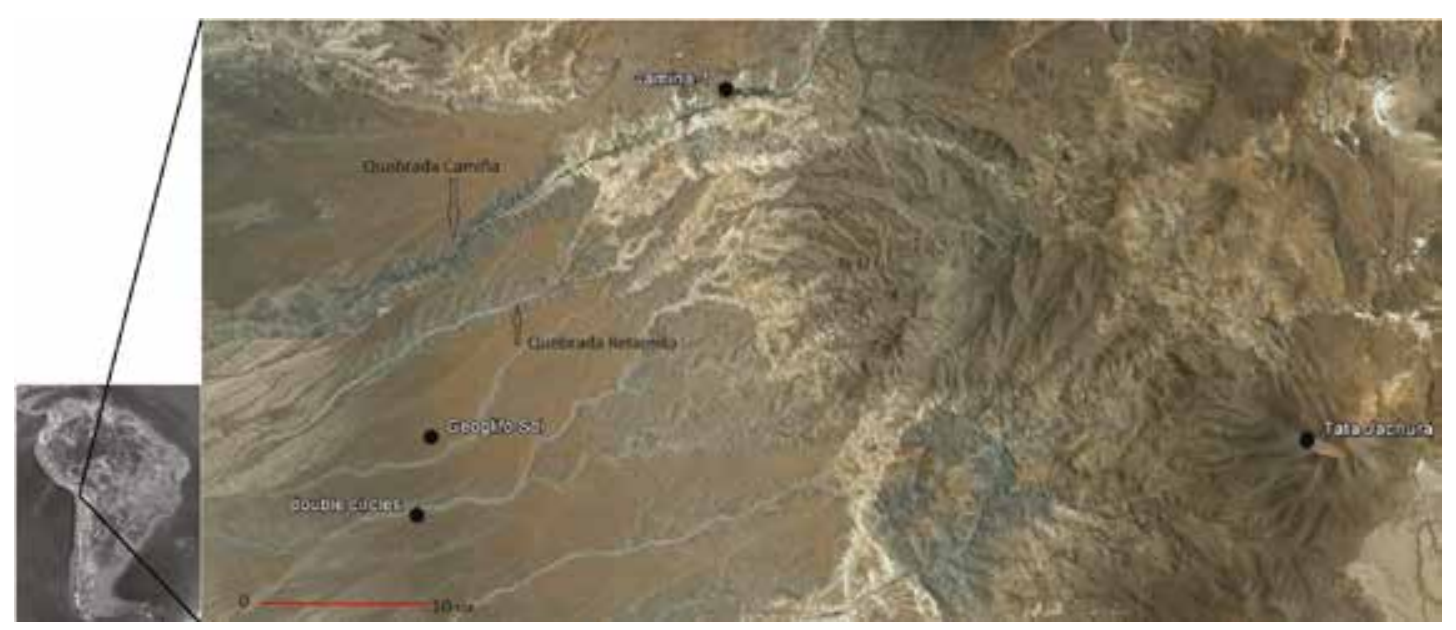

Figura 1. Ubicación de Geoglifo Sol, Norte de Chile. 


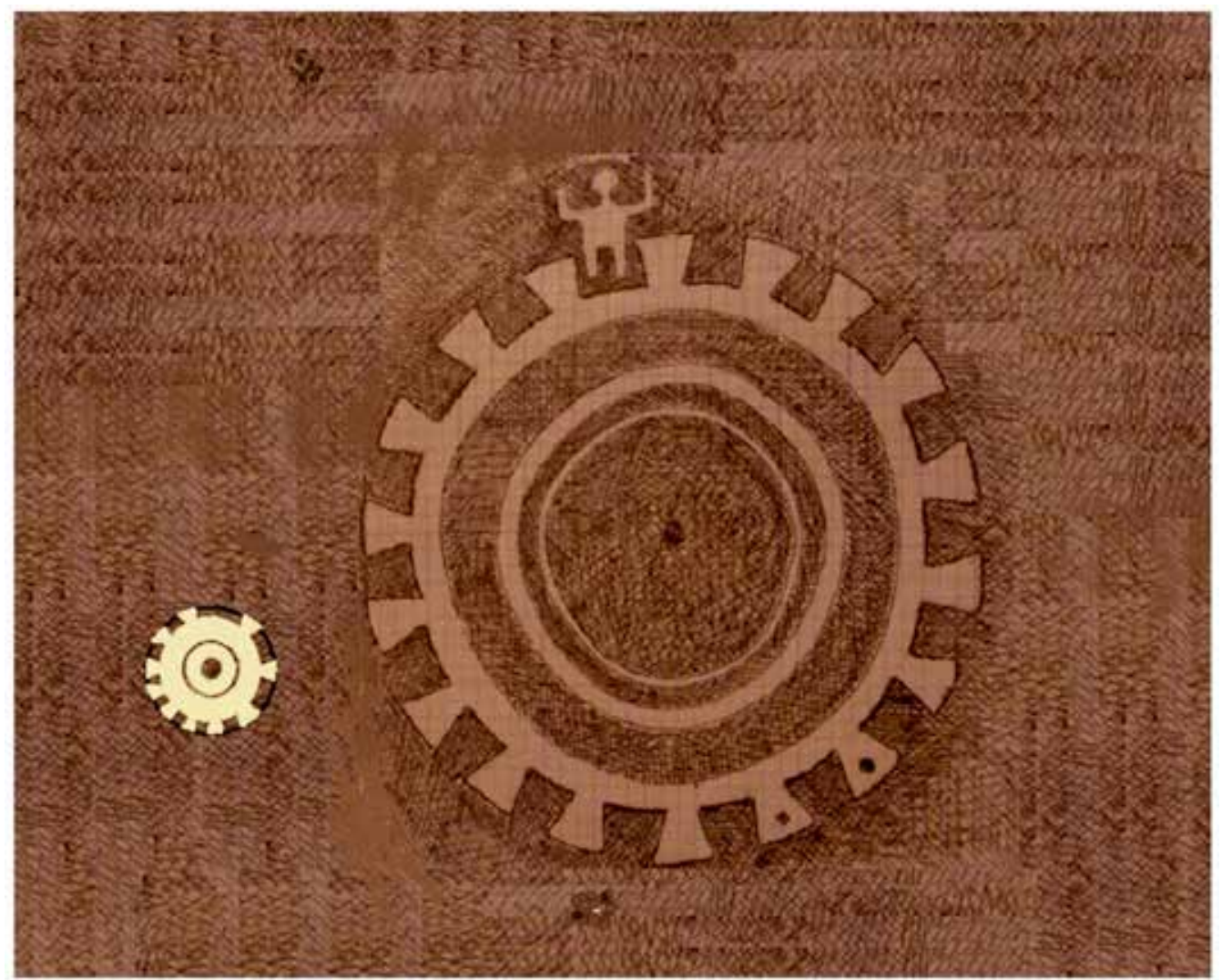

Figura 2. Geoglifo Sol (dibujo L. Briones y P. Clarkson).

se origina en el lago Titicaca acompañado por otras deidades menores de las montañas (Reinhard 1985:306). Los humanos que sirven como agentes de los dioses son los shamanes y curanderos, quienes reciben asistencia de las deidades en forma de aves (Arguedas, 1956; Núñez del Prado, 1979; Tello y Miranda, 1923).

En un análisis fino y multidimensional, Chacama y Espinosa conectan el creador andino Viracocha con la deidad Tarapaca, considerado equivalente al Tunupa. Las imágenes asociadas con Tarapaca aparecen por primera vez en el período Pukara (200 a.C.-200 d.C.) en la región de lago Titicaca y más tarde en la Puerta del Sol de Tiwanaku (16 $36^{\circ}$ 'S) y están identificados en el arte rupestre a los sitios de cerro Unita y Ariquilda 1 en el Norte de Chile. La ruta mítica atravesada por Tarapaca desde el lago Titicaca hasta la costa, pasa por el Norte de Chile donde hay una profusión de senderos de caravanas marcando la conexión entre las tierras altas y tierras bajas, por motivo de subsistencia y trueque ritual en miles de años. Además, los espíritus de las montañas (Aymara mallkus, Quechua apus) en los mitos de Viracocha, incluyen Illimani, Sabaya, Sajama, Guanapa y Taapaca (Chacama y Espinosa, 1997). Los mallkus son importantes en la mitología andina y el Illimani, entre otros, está incorporado en la cosmología de Tiwanaku (Vranich, 2006).

\section{Cosmología y astronomía}

La identificación de artificios para ver, marcar o conmemorar, en la cultura material, demanda una forma físicamente propia en un contexto cultural (Aveni, 2008). Entre las latitudes que demarcan los trópicos (entre $23.5^{\circ} \mathrm{N}$ y $23.5^{\circ} \mathrm{S}$ ), los conceptos desarrollados por las culturas nativas americanas para la observación de cuerpos celestiales eran diferentes de los conceptos desarrollados en astronomía científica, que tiene derivación de las latitudes nortes. Al norte (y sur) de los trópicos los objetos celestiales parecen girar por los polos celestiales (por ejemplo, el Polaris). Entre las latitudes tropicales, los objetos celestiales parecen moverse en línea recta donde el 
observador se siente ser el centro de su universo. Los objetos celestiales están observados o marcados a lo largo del horizonte, dando lugar al concepto de una orientación vertical y un cielo partido entre dominios arriba (visible) y abajo (invisible). Los cálculos astronómicos y calendáricos precisos son relativamente fáciles de obtener con aparatos sencillos para ver y marcar hasta el horizonte, y en el horizonte (Aveni, 1980). Además, Isbell (1982:356-7) nota tres principios de organización estructural común a las cosmologías tropicales de las Américas: 1) los senderos celestiales del sol, luna y estrellas están concebidos como fuerzas cósmicas cuyas interacciones múltiples tienen responsabilidad por la transición del tiempo, el ambiente, el ciclo agrícola y los estados de existencia humana; 2) el ambiente del espacio secular y sagrado, construido y conceptualizado por humanos, es una reflexión de los movimientos y rutas celestiales; 3) el movimiento de las fuerzas resulta de "dos principios dinámicos y opuestos", que tienen la responsabilidad de mantener la tensión entre las fuerzas culturales y metafóricas (hombre/mujer, día/noche, etc.). Estas fuerzas circulan alrededor del Axis Mundi (p.ej., el árbol del mundo, el cerro cósmico, etc.).

Esta dualidad cósmica promueve una epistemología simétrica, doble y reversible, por ejemplo la documentada comprensión y uso del concepto de cenit y anticenit por los incas (Isbell, 1982; además Zuidema, 1981; Urton, 1981; Dearborn y Schreiber, 1987; Aveni, 1981, 1992).

Los solsticios y equinoccios están frecuentemente considerados como las divisiones obvias de los calendarios tradicionales y ellos son, por cierto, eventos notables (Orlove, 1979). Tales divisiones no coinciden necesariamente con las necesidades rituales y predictivas de los andinos de subsistencia y otros ciclos (Isbell, 1982). Unos calendarios nativos de los andes y los trópicos están basados en la observación del sol y los puntos extremos observados en el horizonte. Existen dos tipos de tal calendario, uno basado en los solsticios y equinoccios y otro basado en el tránsito solar del cenit. Los solsticios marcados en el horizonte por estructuras, marcadores o puntos naturales del horizonte, son indicaciones públicas para advertir el cambio de estación. En un calendario basado en el tránsito por el cenit -un fenómeno que ocurre solamente entre las latitudes tropicales- los tránsitos cenit y anticenit proporcionan una alternativa al uso de los solsticios y equinoccios para cuadrar el año, además llegan a una división que pertenece a las estaciones más naturales y de uso. Unas divisiones alternativas del calendario han sido sugeridas, basadas en las realidades de subsistencia en la vida andina. En el Norte de Chile el calendario anual está conceptualizado en tres divisiones con una incorporación de los componentes críticos del ciclo agrícola: seco/ sembrar, mojado/cultivar, cálido/cosechar (Gavilán y Carrasco, 2009:108). En el Perú central, Urton (1981b:29) se refiere a dos divisiones principales de estaciones, lluvioso y seco, con subdivisiones entre cada estación por las tareas agrícolas, pastoriles, etc.

Los calendarios rituales, basados en el horizonte, son bien conocidos en el espacio y tiempo y tales calendarios han sido documentados en comunidades andinas modernas. Urton (1981a:114-116) ha indicado una consideración importante sobre la precisión de los calendarios tradicionales basados en el horizonte: los rasgos distintivos y topográficos del horizonte son usados como puntos de referencia por los cuerpos celestiales. Cada comunidad reconoce los cuerpos celestiales que tienen relevancia en su ubicación y el cronometraje de las tareas de subsistencia; los lugares más conocidos y ritualísticos como las cumbres de los cerros (mallkus/ apus) pueden ser combinados con los lugares muy conocidos y seculares como la dirección a un pueblo. Las investigaciones tempranas en el estudio de "astroarqueología" ponían énfasis en las medidas precisas (Hawkins, 1964; Thom, 1967, 1971), y tal precisión es disonante en el contexto de una dependencia sobre puntos topográficos que son inmóviles y bien conocidos.

La significancia de las deidades y fenómenos meteorológicos en la cultura andina tiene relevancia en el uso de calendarios nativos para la observación astronómica.

...late one afternoon while doing fieldwork in the community of Misminay, Peru, a thirteen-year-old boy with whom I was pasturing sheep volunteered the information that, in preparation for planting, everyone in the community was watching the stars called Collca ("storehouse") very closely each night.... I asked why everyone was watching Collca. His answer, accompanied by a sharp glance, was simple: porque queremos vivir... (Urton, 1981b:3).

La incorporación de la astronomía en ritos y sitios está bien documentada en los periodos 
precontacto y postcontacto en la región andina (p.ej., Bauer, 1998; Bauer y Dearborn, 1995). La documentación es particularmente rica para los Incas, donde hay archivos coloniales, españoles e Incas que proveen fuentes de investigación, más comparativas con estructuras arqueológicas y datos etnográficas (Zuidema, 1962; Urton, 1991b; Aveni, 1997; Bauer, 1998). En el tiempo de los Incas se han aplicado metodologías consistentes entre los contextos culturales, documentales y conocidos. Estos métodos han indicado la significancia de la astronomía en la cultura Inca. Según fuentes de archivos tan variados como el documento Inca Pachacuti Yamqui de 1613, en donde sabemos que los Incas observaron el sol, la luna, Venus, y las Pléyades, y posiblemente, Orión y La Cruz del Sur. En trabajos arqueológicos en los sitios rituales como el Coricancha en Cuzco, se sabe que los incas incorporaron conceptos astronómicos en la arquitectura del templo (Aveni, 1997:150). Los estudios etnográficos en las tierras altas del Perú han establecido un traslape de los fenómenos celestiales por la gente antigua y moderna. Los fenómenos incluyen las estrellas, constelaciones y planetas, más aún, con sus nombres y significancias de los cuerpos celestes (Urton, 1981a, 1981b, 1983). En la región del lago Titicaca la arquitectura ritual desde los últimos siglos a.C. y en el sitio de Tiwanaku están alineadas con los fenómenos del solsticio, equinoccio, cenit, y nadir, con la Cruz del Sur, Antares (la estrella más brillante en el Escorpio) y el $\alpha$ y $\beta$ Centauri en la Vía Láctea, con las montañas prominentes (Vranich, 2006, comunicación personal). Estos tipos de congruencias están relacionados a los modelos de continuidad documentado por las poblaciones andinas del período pre y postcontacto.

En otra parte de la región andina las comparaciones entre los cuentos coloniales y etnográficos proveen información substancial sobre la incorporación del cosmos y los cuerpos celestiales dentro de la vida secular y sagrada, si es verdad que podemos separar los conceptos. La incorporación de la astronomía, como un componente esencial de lo complejo de la información necesaria para los agricultores y pastores en la planificación del próximo ciclo de subsistencias, está bien documentado para las tierras altas y el altiplano del Perú y Bolivia, pero hay un escasez de información para la gente del Norte de Chile (Urton, 1981a, 1981b; Yampara, 1992; Tudela, 2000; van Kessel y Enríquez, 2002; Gavilán y Carrasco, 2009).
La interacción de los fenómenos observados de que el uso de la astronomía sirve para una sola parte, es compleja y sofisticada; el concepto de "la sabiduría de la gente" asume una connotación muy culta, por ejemplo en la consideración de la disposición tradicional de la época de sembrar está enlazado con la condición de la aparición de las Pléyades y la verificación científica de la relación de la visibilidad de las Pléyades y las condiciones para sembrar (Orlove et al., 2000). La ausencia de información específica está ameritada por el hecho de que las observaciones astronómicas son componentes esenciales en la vida andina, con evidencia de una similitud de los fenómenos celestiales observados en decenas de comunidades desde el altiplano hasta la costa (véase van Kessel y Enríquez, 2002) y por eso podemos inferir un nivel de consecuencia de las prácticas y creencias entre la gente tradicional precontacto y moderna. Desde luego, hay conocimientos e informaciones perdidos en el tiempo, como está demostrado por la muerte de los últimos usuarios de observaciones de los solsticios en la comunidad de Maquercota en la orilla del lago Titicaca en la provincia de Puno, Perú (van Kessel y Enríquez, 2002:82-3). Las diferencias significativas entre la selección de uno u otro cuerpo celestial están ubicadas en la medida de las observaciones y sus acciones, porque las cosas importantes de medir las actividades relacionadas a la subsistencia (agricultura y pastoreo) están relacionadas a la latitud y altitud. La disposición de las actividades también afecta la sincronización de la organización de los eventos celestiales con los santos mayores de cada comunidad y región.

Estudios arqueológicos indican la presencia e influencia en el Norte de Chile de las culturas del origen del lago Titicaca y Tiwanaku (Muñoz, 1989; Berenguer y Dauelsberg, 1989; Rivera, 1991). La presencia subsiguiente de los Incas en la misma región está advertida en la inclusión de Tarapacá, entre el sector Collasuyu del dominio Inca del Tawantinsuyu (Mundo de los Cuatro Cuartos). Unas comunidades modernas en la región del lago Titicaca usan una variedad de observaciones celestiales y fechas que son necesarias para mantener un equilibrio apropiado entre la comunidad (runa), las deidades (wa'ka) y el ambiente (sallqa). Hay una coincidencia de las observaciones celestiales y las fechas con las anotadas en las regiones, entre el exdominio de los Incas en el Perú, además confirmando la continuación hasta hoy de la vida cultural 
andina, a pesar de la evidencia obvia del impacto de los españoles y los cristianos.

Los modelos evidentes en las sociedades andinas ya mencionadas han sido aplicados a las sociedades andinas precontactos en donde por ejemplo un cuerpo rico de simbolismo existió entre las culturas de la región del lago Titicaca. Mientras que en la región del cuadripartido Tawantinsuyu, donde el Collasuyu de los incas abarca las regiones del lago Titicaca en Bolivia y Tarapacá en Chile, estos no fueron precursores en la incorporación de conceptos astronómicos en el arte, arquitectura y la sociedad; sí fueron agentes y elaboradores de un padrón antiguo de la vida andina. El sitio del periodo Horizonte Medio de Tiwanaku cerca del lago Titicaca, más los predecesores y los siguientes, también compartieron con el padrón antiguo de vida andina. El tránsito solar del cenit y anticenit (o nadir) en el sitio de Tiwanaku divide el año en partes casi equivalentes, que según Zuidema (citado por Isbell, 1982; Zuidema, 1981) era un componente esencial en el desarrollo de la cultura andina. La presencia poderosa de Tiwanaku (y las culturas relacionadas en el altiplano boliviano) está bien documentada en el Norte de Chile, y al igual que el intercambio de ideas, facilitado por las antiguas rutas de caravanas de camélidos (Figura 3) que sirvieron para mover bienes entre el altiplano, los oasis en los desiertos del interior -incluso Tarapacá- y la costa del Pacífico (Núñez y Dillehay, 1995).

\section{Tarapacá: caravaneros y geoglifos}

Entonces, en el área andina existen unos ejemplos bien documentados de la incorporación de la astronomía y observaciones celestiales en el tiempo y espacio, por medio de mitos, rituales de vida, rituales de viaje y muerte y más allá de la vida. En la región de Tarapacá, en el Norte de Chile, hay una información insuficiente sobre astronomía de los antiguos habitantes, manifestándose más concretamente entre el 400-1000 d.C., coincidente con el dominio de Tiwanaku. Sabemos también que el viaje rutinario de las caravanas de camélidos por la región son anteriores a la fecha de la presencia de Tiwanaku y otras culturas en el área del lago Titicaca y que continuaron activándose después, con el impacto directo de Tiwanaku y con el surgimiento de los diferentes estados regionales en el área.

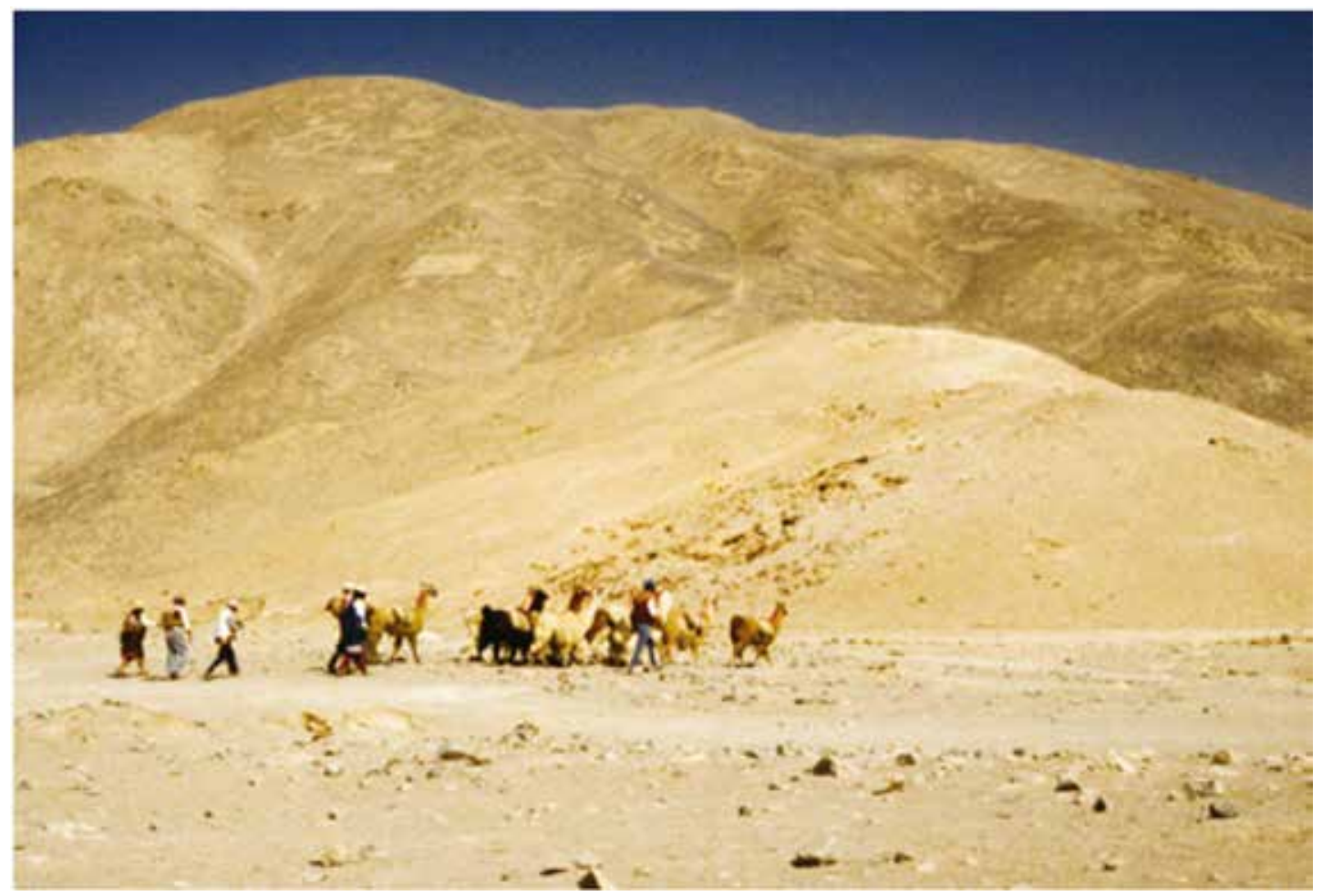

Figura 3. Caravana de camélidos pasando por Cerros Pintados, Norte de Chile en 2000 d.C. (foto P. Clarkson). 
Los restos arqueológicos asociados a las caravanas están, por definición, limitados (Clarkson y Briones, 2001). Los caravaneros frecuentan los mismos lugares para descansar, particularmente los lugares con agua, pasto, y seguridad de los predadores (Nielsen, 1997-8). Las estructuras simples y permanentes como los fogones y camellones están testimoniando la presencia de viajeros en la pampa, aunque si bien la edad de tales estructuras son imposibles de determinar. Los estudios etnográficos de caravanas andinas indican que en algunas ocasiones se llevan a cabo rituales en la ruta, sin embargo la naturaleza del viaje en caravana implica que cualquier material o peso extra es costoso, tanto para la economía del trueque como para el bienestar de las llamas. Los artefactos asociados con los rituales caravaneros probablemente son similares a los utilizados en sus casas (Nielsen, 1997-8:173). Además, las cosas y actividades asociadas con los rituales son alusivas al registro arqueológico. Los rituales asociados con quemas están documentadas etnográfica y etnohistóricamente en la cultura andina, y cualquier resto de quema desaparece en condiciones expuestas por el viento, sol, y animales como aves, carnívoros e insectos. Similarmente, los materiales orgánicos y de asociación conocida con los rituales caravaneros, por ejemplo, las plumas de flamenco es probable que se encuentren in situ. Las ofrendas no orgánicas conocidas al paso de los caravaneros modernos incluyen cobre, malaquita, concha y cuentas. La presencia de tales materiales asociadas con los senderos caravaneros y geoglifos está identificada con una significancia ritual (Nielsen, 1997-8:173; además Berenguer, 1994; Neilsen, 1989; Neilsen, 1997; Sinclaire, 1994). Como Nielsen (1997-8:172) indica, se puede inferir un significado ritual, pero no como una intención clara por parte de los caravaneros.

Entre los restos arqueológicos inmuebles más abundantes en el Norte de Chile están los geoglifos, los que se contabilizan por miles en el desierto de Tarapacá. La asociación física de los geoglifos con los senderos caravaneros da evidencia clara de la asociación en espacio y tiempo, sin hacer caso de cuándo cualquiera de los dos han sido hechos o usados. Como Núñez ha indicado congénitamente, el acto de crear los geoglifos (y otras formas de arte rupestre) indica un ritual (Núñez, 1985:244; además véase Núñez y Briones, 1967-8; van Kessel, 1976:234; Chacama y Espinosa, 1997:30). Siguiendo a Nielsen (1997-8: 173), "una de las características del ritual es la reproducción de cosmovisiones y premisas de acción de las que participan los miembros de una sociedad, [entonces] cabe esperar que los ámbitos rituales contengan rasgos de cierta durabilidad y que sean reusados". Consecuentemente, debido a que los geoglifos tuvieron una clara intención en el ritual caravanero y que fueron hechos en espacios abiertos, accesibles y protegidos, por medio de métodos durables, ellos no solo son reutilizables, sino que son puntos centrales de rituales, a modo de huacas. Además, se pone énfasis en otro elemento significativo en la consideración de los geoglifos en la vida andina, como lo articulado por Sepúlveda et al. (2005:226), "que arte rupestre y los otros componentes culturales deben ser integrados para avanzar en la comprensión de los procesos socioculturales ocurridos en el Norte de Chile".

\section{Geoglifos andinos y cosmología andina}

La matriz de las montañas, historia, subsistencia y cosmología entretejidas con la vida andina provee un fondo para la consideración del Geoglifo Sol como un artefacto de astronomía cultural (Figura 4).

El Geoglifo Sol es extraordinario por su composición, ubicación, y estilo. En realidad se refiere a la composición como un "panel", porque hay un conjunto de varios elementos que parecen asociados. El panel está ubicado en un plano horizontal de la pampa en un sector naturalmente liso. La mayor parte del panel está ocupado por un grupo de círculos concéntricos, el más grande y más exterior está formado por dieciocho almenados con un diámetro de $20 \mathrm{~m}$. En el lado este, entre dos almenados se registra una figura antropomorfa con los brazos hacia arriba; los antropomorfos son minoritarios, pero significativos. Se nota que el antropomorfo está sesgado hacia el este y no por el radio del círculo (Figura 2).

Los elementos adicionales del panel están ubicados alrededor del círculo mayor. A $4 \mathrm{~m}$ al norte hay un círculo menor, también almenado. El círculo menor mide 3,5 $\mathrm{m}$ de diámetro y tiene tres círculos concéntricos y nueve almenados exteriores. $\mathrm{Al}$ oeste hay un montón de piedras de $0,3 \mathrm{~m}$ de altura, y otro montoncito al noreste. Es imposible demostrar una asociación entre todos los elementos del panel, pero la similitud entre la miniatura del círculo almenado y el círculo mayor es inconfundible.

El estilo único de los dos círculos almenados es una evidencia adicional de una asociación intencional 


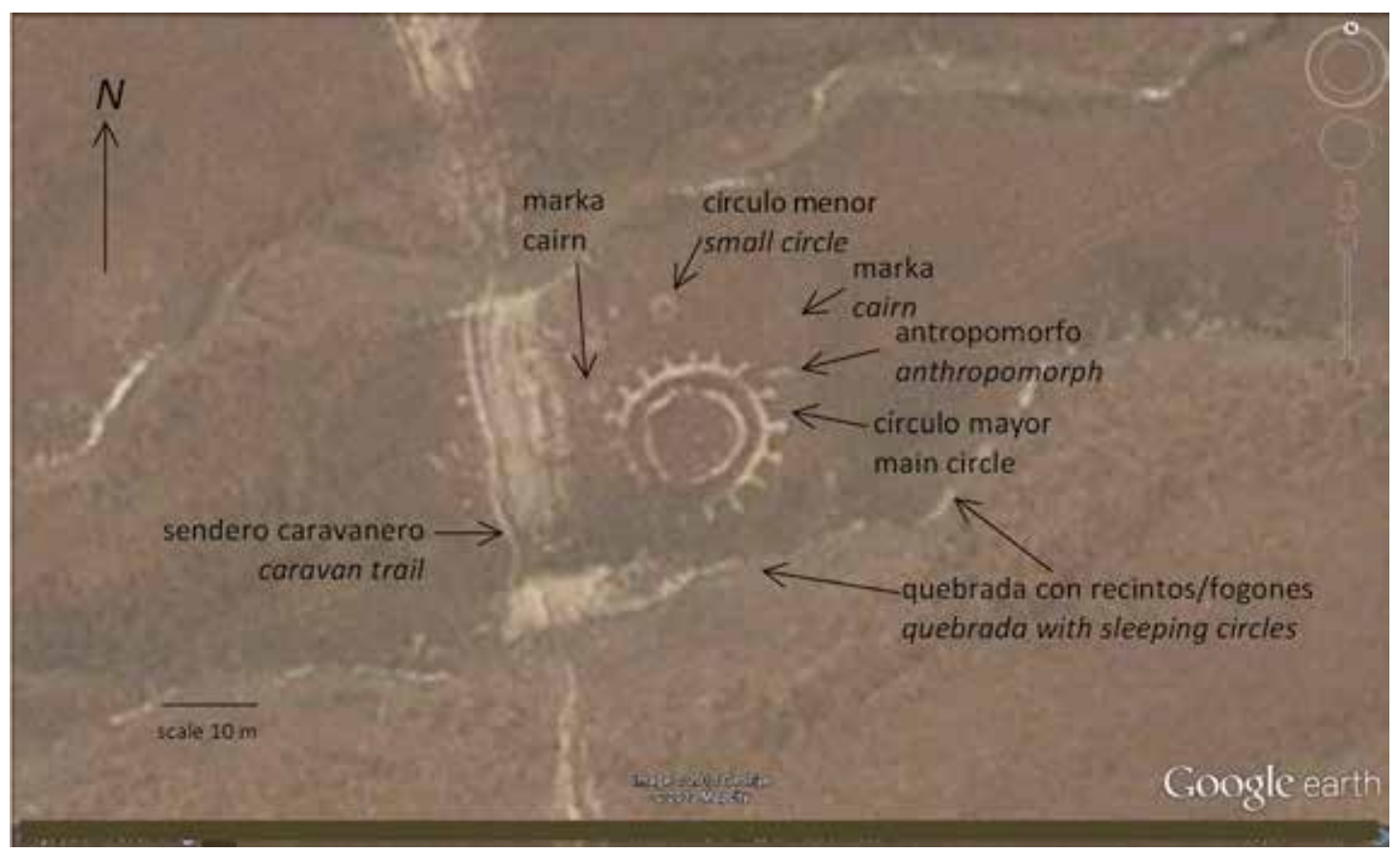

Figura 4. Geoglifo Sol, foto aérea (Google Earth).

de los elementos del panel. Los geoglifos circulares en el norte de Chile no son desconocidos, como tampoco son los geoglifos situados en superficies horizontales; los círculos almenados no son comunes. Existen unos ejemplos semejantes de El Vado en la quebrada de Guatacondo, en Cerro Rosita [ex-Abra/ Aura], en cerro Inti en el oasis de Pica y en Alto Sur de la desembocadura de la quebrada de Camarones (Figura 5). Geoglifos circulares hechos en estilos similares son conocidos en localidades distantes por los mismos senderos (Briones y Chacama, 1987), pero con diferencias en el estilo y técnica de confección, por lo que no se les puede comparar. El geoglifo de Cerro Rosita está situado en la ladera de un cerro orientado al este, el del Alto de Camarones está esbozado con pigmentación roja, sobre un plano visible desde el lugar, los geoglifos de cerro Inti que se registran en una ladera orientada al sur y el geoglifo de Guatacondo en un plano visible desde la colina inmediata. Es interesante ver dos círculos en el horizonte al lado de un sendero auxiliar de Geoglifo Sol, unos $5 \mathrm{~km}$ al sur (Figura 6).

Hay una sugerencia final para una conceptualización intencional de los varios elementos del panel. Extraordinariamente, no hay restos culturales en todo el área llana, incluyendo solo el panel y salvo un número escaso de fragmentos de tiestos cerámicos precontacto, entre uno de los almenados; es necesario recordar la costumbre antigua y moderna de los andinos (además los grupos tropicales amazónicos) de limpiar los espacios rituales. Frecuentemente los geoglifos situados cerca de los senderos tienen restos culturales. Uno de esos restos puede ser por casualidad, por ejemplo: los fragmentos de tiestos o una flecha perdida por un cazador; la presencia de restos como minerales (cobre, malaquita), conchas, y cuentas -además los tiestos y líticos- son indicadores de ritual (Nielsen 1997-8). Ambos, más otros geoglifos y estructuras en el sector, como el sendero al lado del Geoglifo Sol, hasta la quebrada Retamilla (aproximadamente $5 \mathrm{~km}$ al norte), se observan superficialmente restos culturales pre y postcontacto. Esto es un testimonio de la presencia humana de precontacto con el Geoglifo Sol, con el sendero caravanero y la presencia por otra parte "normal" de los restos culturales asociados.

La combinación de todas las características ya mencionadas sugiere una representación única y de contenido ritual. La situación física de este geoglifo único y solitario, más una visual del horizonte no interrumpido, incluso montañas conocidas por sus leyendas y mitos, como lugares de alta importancia en la vida de los agricultores y pastores antiguos y modernos, adquiere una importancia ritual y 


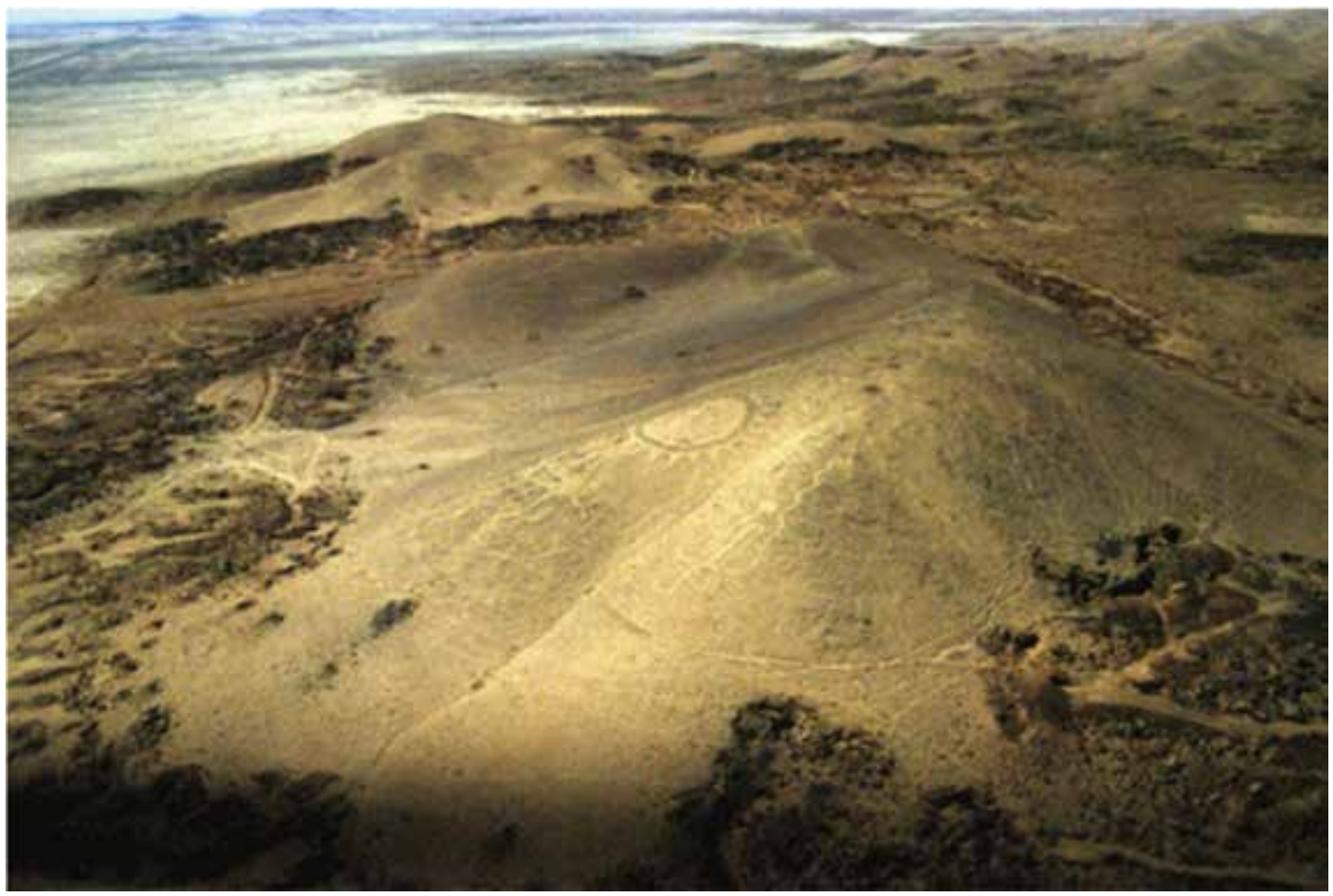

Figura 5. Geoglifo circular, Cerro Rosita, Norte de Chile (foto L. Briones).

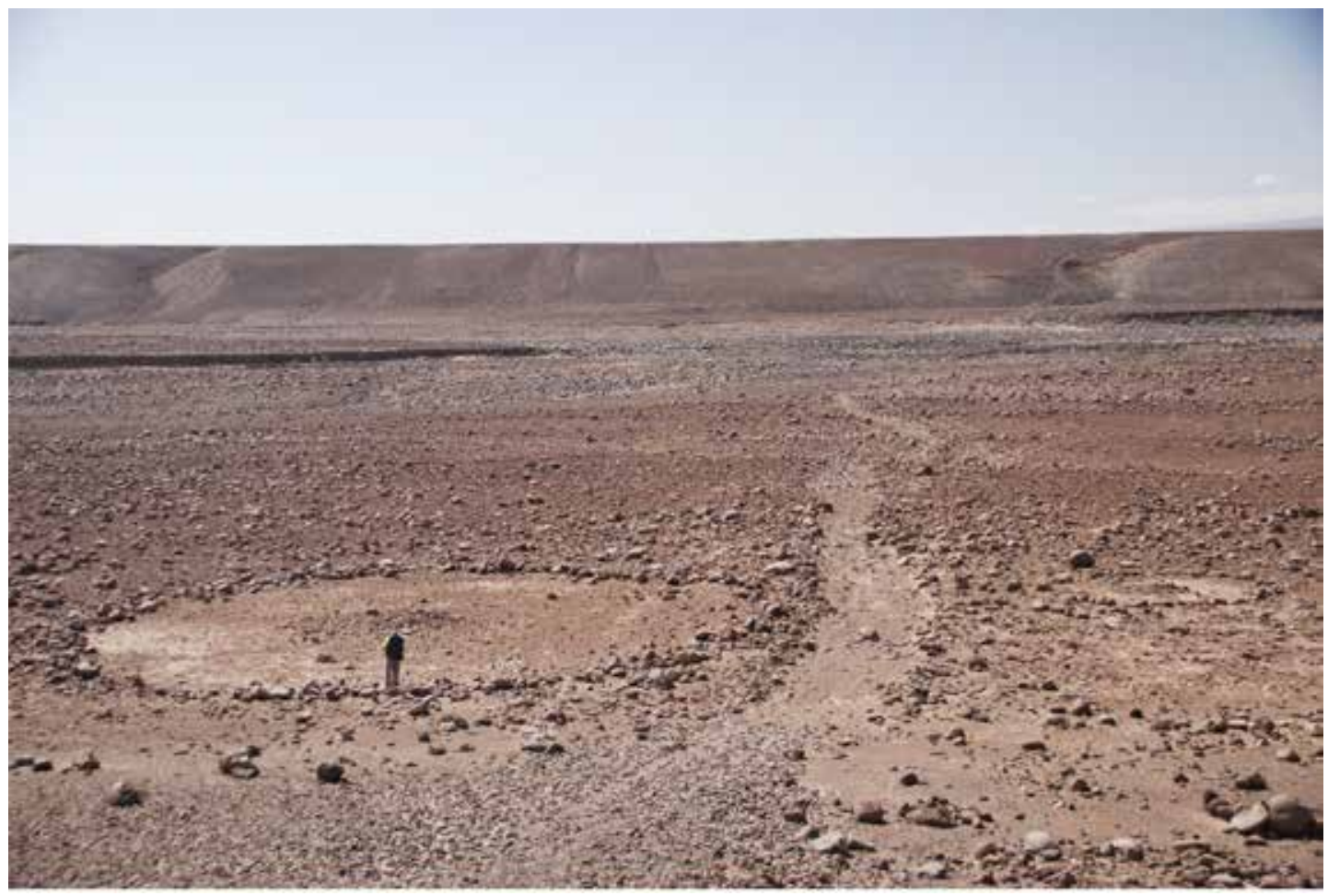

Figura 6. Geoglifos circulares, $5 \mathrm{~km}$ al sur de Geoglifo Sol, al mismo lado del sendero caravanero del Geoglifo Sol (foto P. Clarkson). 
simbólica en el contexto total de la geografía local. Consideramos unas interpretaciones cosmológicas del geoglifo en el contexto de la astronomía cultural, lo que abarca el contexto social más el rol de astronomía en la vida secular y sagrada (Ruggles y Saunders, 1993). Cualquier discurso del Geoglifo Sol debe incluir el contexto andino.

No hay dudas que el Geoglifo Sol era visible $\mathrm{y}$ visitado por cualquiera persona pasando por el sendero caravanero, no obstante la escasez de restos culturales. El geoglifo tiene mejor posibilidad de ser observado con luz rasante, ya sea de la mañana o atardecer y está situado a escasos cuatro metros del sendero principal (Figura 7). Además, la quebradilla contigua con el sector del geoglifo tiene varios recintos pequeños o "camadas" de fecha desconocida. Tales recintos sirvieron y sirven para protegerse y abrigarse del frío y viento nocturno (paskanas), con el posible apoyo de un improvisado fogón (Figura 8).

La importancia de los elementos únicos ya anotados están subrayados por una vista panorámica, desde el Geoglifo Sol, de las montañas (Figura 9). Podemos agregar 1) el significado de las montañas en el horizonte, desde una visión andina, 2) el uso de algún tipo de aparato para conmemorar y localizar objetos celestiales, tanto por los Incas y los Tiwanakus, ambas culturas con dominios en el desierto de Tarapacá, y 3) la documentación etnográfica de la dependencia con observaciones celestiales para marcar algunas fiestas y actividades de subsistencia, existiendo las condiciones ideales en el sitio del Geoglifo Sol para observar los cuerpos celestes.

La escasez de información sobre el uso de astronomía en contextos etnográficos, etnohistóricos, y arqueológicos en la región de Tarapacá nos plantea algunas dificultades. No sabemos lo extenso de la influencia de los Incas o culturas circum-Titicaca sobre la cosmovisión actual de los tarapaqueños: los Incas reescribieron la historia para su glorificación.

Un examen cauteloso de los eventos y cuerpos celestes documentados en las culturas andinas nos da un espacio desde donde podemos considerar las propiedades rituales del Geoglifo Sol entre los años de 400-1500 d.C., un periodo que corresponde al tiempo de los Tiwanku, de los Desarrollos Regionales e Inca. Estos cuerpos incluyen el sol (solsticio, equinoccio, cenit, nadir), las Pléyades, $\alpha$ y $\beta$ Centauri en la Vía Láctea, y la Cruz del Sur.

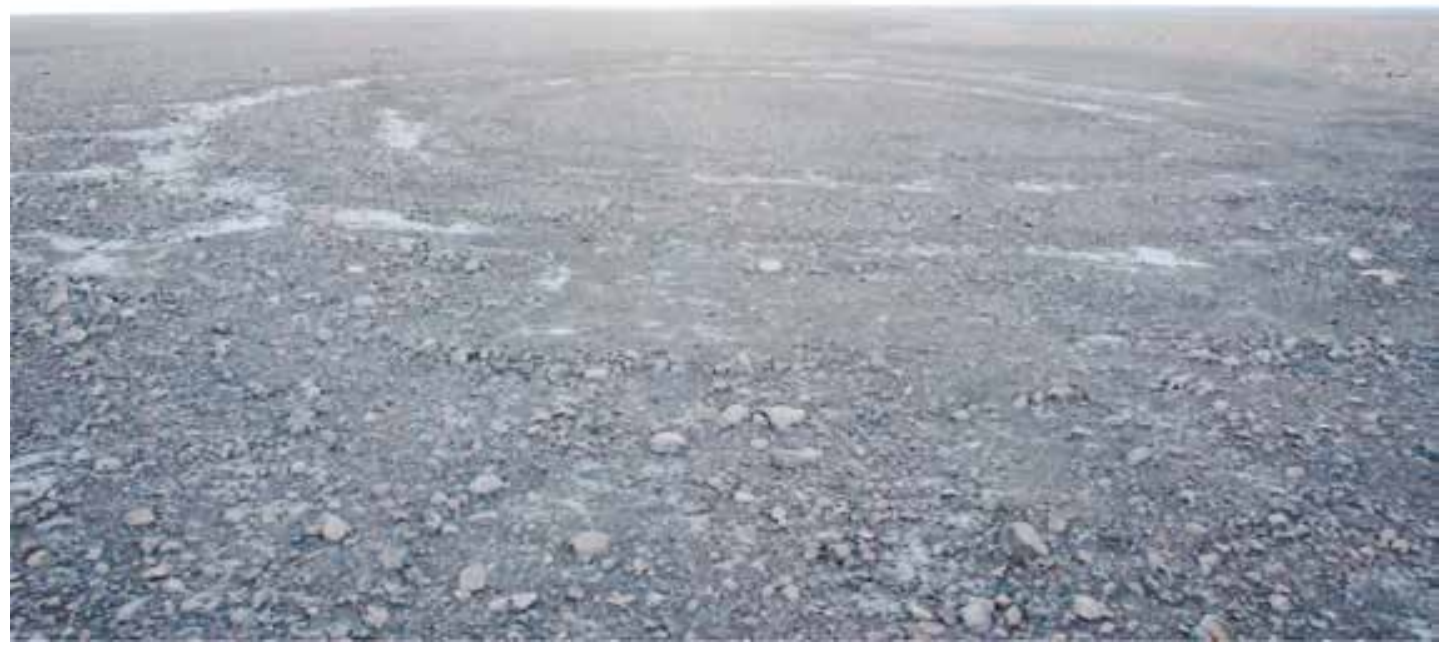

Figura 7. Geoglifo Sol desde el sendero caravanero (foto P. Clarkson). 


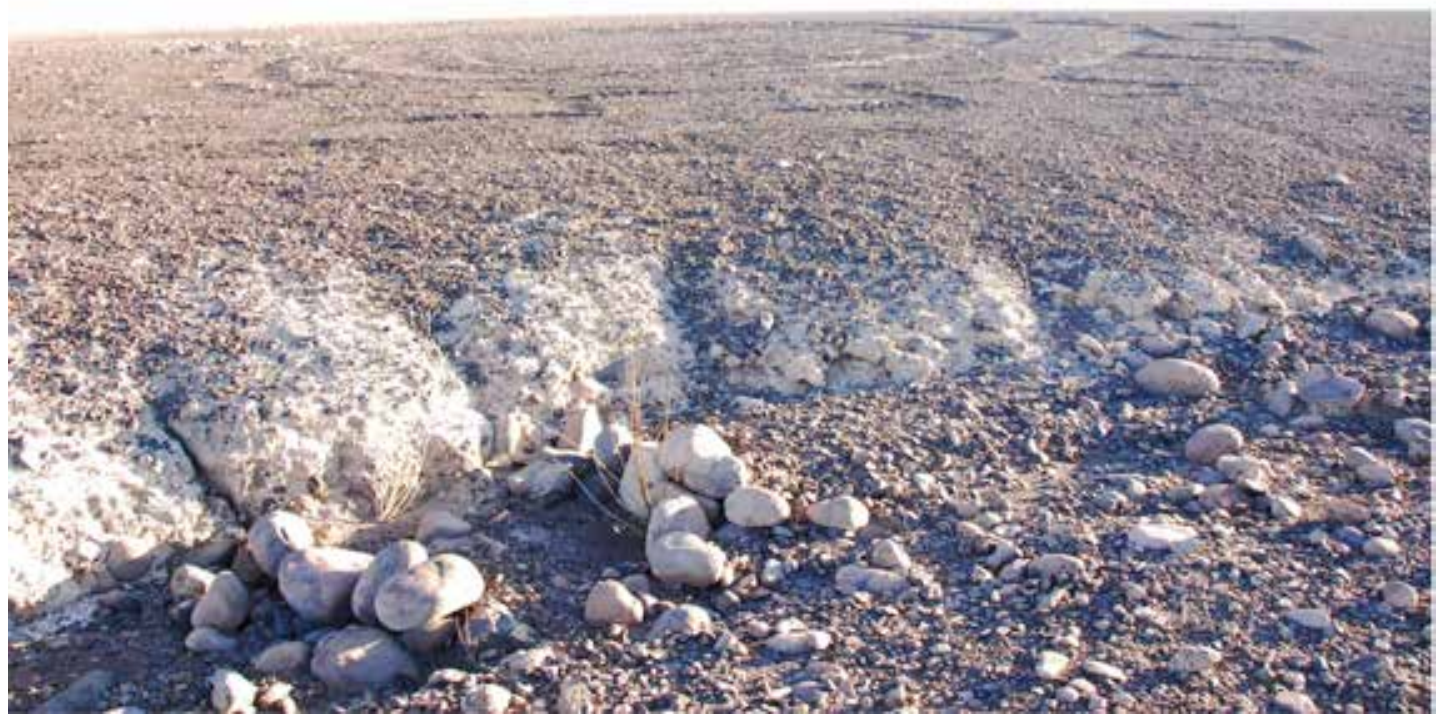

Figura 8. Lugares limpios y adecuados para los recintos o los fogones; se ve el Geoglifo Sol atrás (foto P. Clarkson).

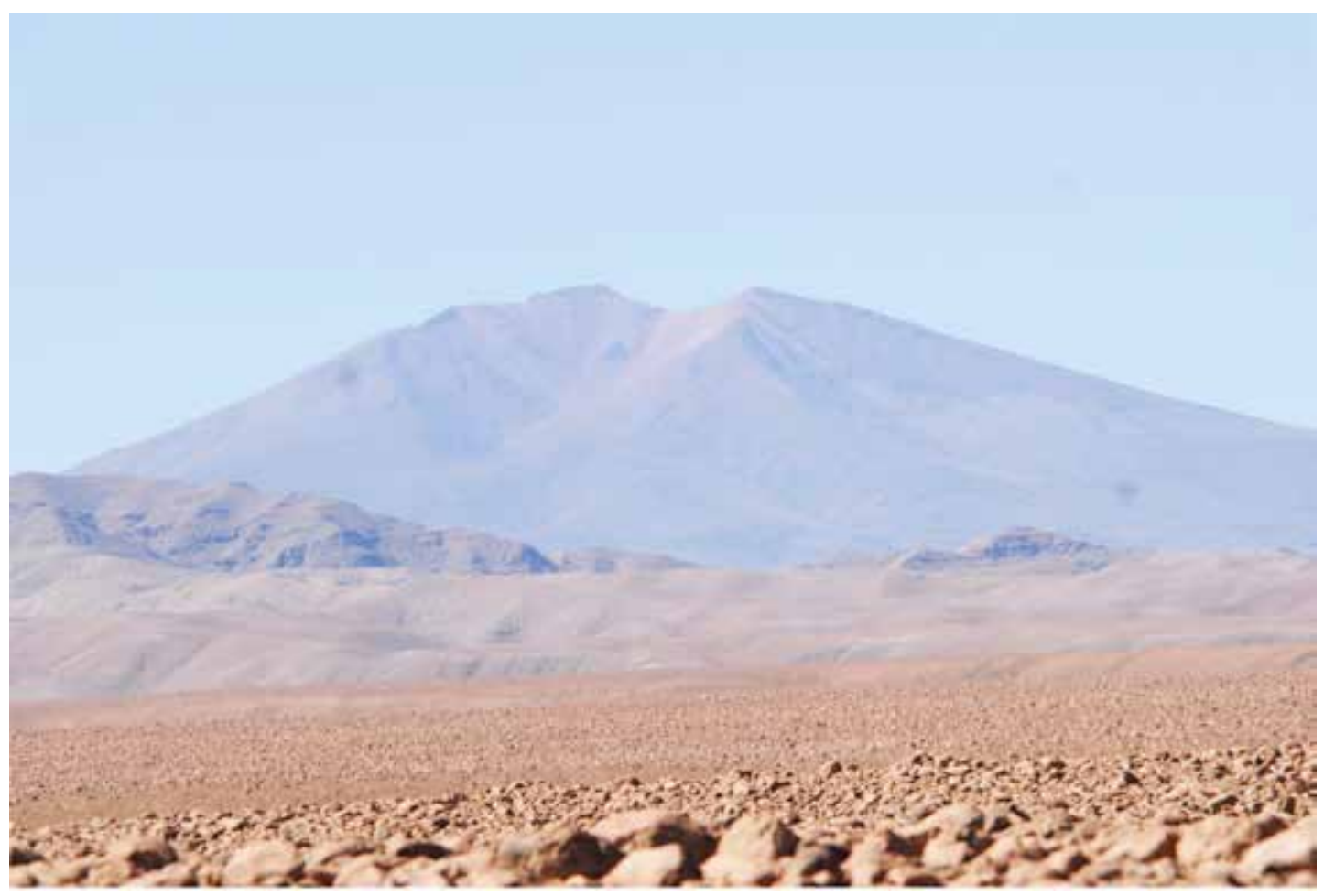

Figura 9. Tata Jachura, desde el Geoglifo Sol (foto P. Clarkson). 
Además, el tránsito por el cenit y posiciones heliacales en el este y oeste; estamos considerando más fenómenos cuando los datos están disponibles; los criterios para determinar las alineaciones están calculados según Aveni (1972). ${ }^{1}$ La Figura 10 muestra algunos fenómenos celestes en contraste con la representación del horizonte. Resalta por el este el volcán Tata Jachura, un mallku de gran importancia en la historia y leyendas del Norte de Chile, además se acota la figura del antropomorfo orientado también al este.

¿Por qué estos objetos celestes? Encontramos una respuesta entre las características de la ubicación y visión desde el Geoglifo Sol en el contexto más grande de las creencias cosmológicas del norte de Chile y el área colindante en los andes. Hay mucha evidencia en la literatura arqueológica, etnohistórica, y etnográfica indicando las correlaciones entre las Pléyades y el período de cultivos (Urton, 1981a; Aveni 1997; van Kessel, 2002), más la incorporación del solsticio de junio con la salida helíaca de las Pléyades. Los estudios etnográficos entre los aymara-hablantes demuestra un énfasis similar con las Pléyades como uno de varios pronósticos para el período de agricultura, además la Vía Láctea, la Cruz del Sur y Escorpio (van Kessel, 2001, 2006; van Kessel y Enríquez, 2002). Mientras que las fiestas y días de los santos corresponde a la historia específica de una comunidad, muchas de las fiestas religiosas coincide con fechas importantes calendáricas y estacionales, por ejemplo la concurrencia de San Juan el 24 de junio con las celebraciones del "solsticio" (Urton, 1981b) y de Santo Tomás el 21 de diciembre. Las fechas del tránsito del cenit/anticenit en la latitud del Geoglifo Sol también presenta correlaciones interesantes con unas fiestas celebradas en el Norte de Chile: San Santiago el 25 de julio (anticenit solar el 26 de julio), y a fines de noviembre en la fiesta de San Andrés (30 de noviembre), generalmente coincidente con el tránsito del cenit solar (20 de noviembre) y el tránsito arriba del $\alpha$ y $\beta$ Centauri en el Escorpio ("los ojos de la llama" en aymara y quechua), marca el fin del período de nacimiento de los camélidos.

Por último, debemos considerar ¿por qué el Geoglifo Sol está situado tan lejos de cualquier comunidad -antigua o moderna-en una región de pocos recursos para la agricultura y pastoreo? Los ejemplos arqueológicos y etnográficos aquí examinados están basados en un modelo de "hombre en el centro del

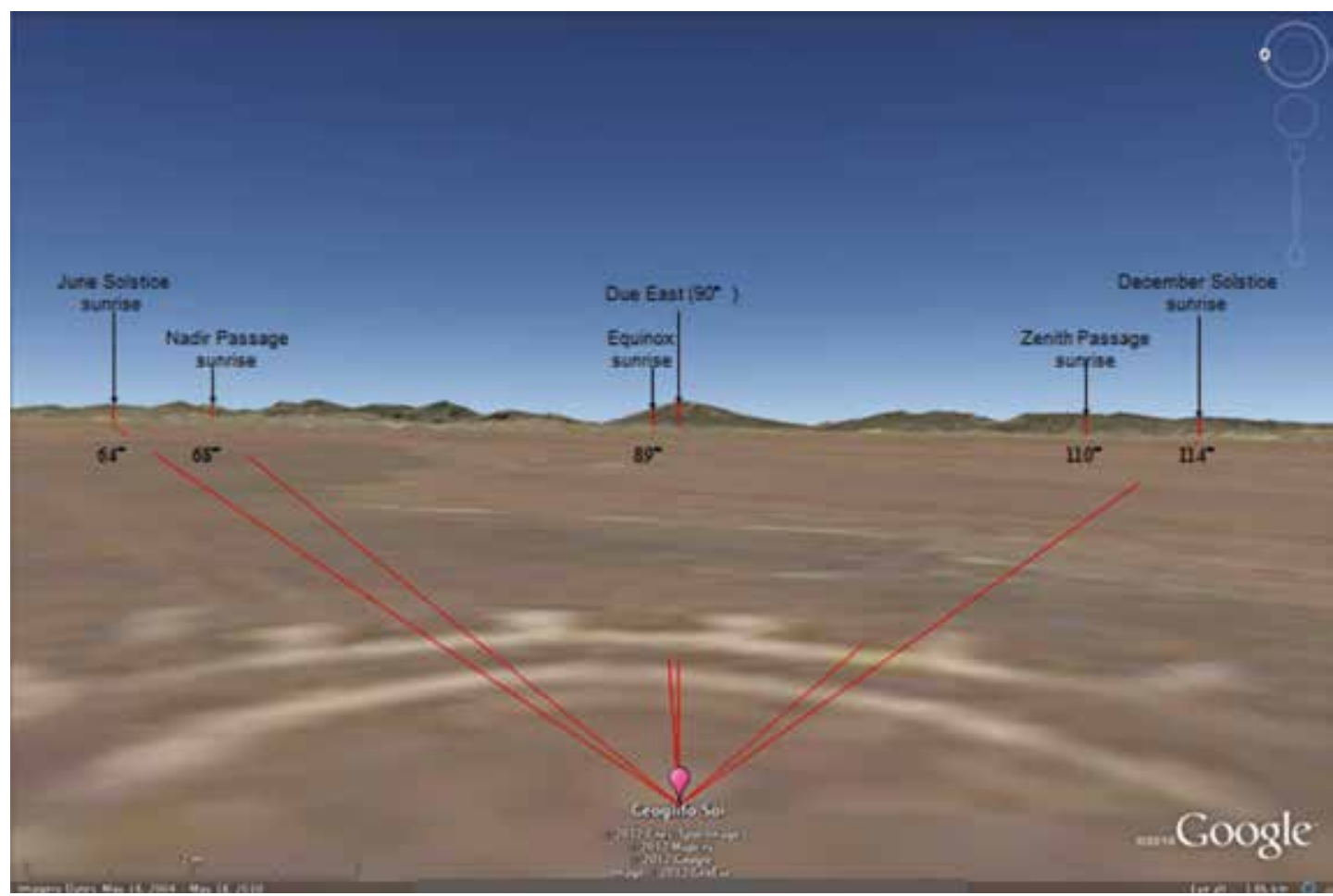

Figura 10. Alineamientos astronómicos en el horizonte este desde el Geoglifo Sol (H. Green). 
mundo" y la incorporación del horizonte, en la creación de los calendarios, basado en el horizonte y que reflejan las necesidades de la comunidad; tal manera de conceptualizar el cosmos está de acuerdo con el modelo de observaciones tradicionales, es decir, el hombre-al-centro de los trópicos. El contexto terrenal del Geoglifo Sol consiste en un sendero al lado que corre en sentido norte-sur y viceversa, conectando al sitio arqueológico de Alto Ariquilda Norte con los caseríos de Calatambo, en la quebrada de Camiña y Suca, en la quebrada homónima. Desde dichos sitios hay senderos adicionales que, en realidad, conectan el Geoglifo Sol con una red física y social entre las tierras altas, desierto, y costa. Los viajes de larga distancia, por parte de los caravaneros, duraban semanas o meses y la topografía del horizonte y los alineamentos desde el Geoglifo Sol pudieron servir como una mnemotécnica para una variedad de comunidades, dependientes de su calendario "local'. Los eventos calendáricos aquí considerados son los mismos documentados por espacio y tiempo en la región andina, lo que le confiere al Geoglifo Sol un uso universal.

\section{Consideraciones finales}

Esta exploración a una función ritual del Geoglifo Sol nos lleva a otra pregunta importante: ¿el Geoglifo Sol es el único geoglifo con una significación astronómica? Y, si este es único, ¿la hipótesis es menos válida? Debido a una insuficiencia de información etnográfica y arqueológica por parte de la gente del desierto de Tarapacá, sugerimos que la respuesta es "no" por ambas preguntas. Las connotaciones rituales de geoglifos en el norte de Chile han sido considerados desde una diversidad de puntos de vista (Núñez, 1976; Bittman, 1985; Reinhard, 1985; Romero, 1996; Chacama y Espinosa, 1997; Briones et al., 1999; Díaz y Mondaca, 1999; Briones, 2006; Vitry, 2007; Pimentel, 2009; Sepúlveda et al., 2010), y el punto de vista astronómico aquí presentado es una nueva faceta en la investigación. Desde la primera creación de geoglifos sobre la superficie del desierto han estado en permanente proceso de reuso, reinterpretación y también de alteración. Las interpretaciones idiosincrásicas están fuera de la capacidad de la arqueología (Neilsen, 1997-8). Sí podemos seguir mostrando en las grandes distancias del desierto de Tarapacá la existencia de ejemplos claros de estilos artísticos e individuales $(<$ biblio $>$ ) y, es importante anotar que el Geoglifo Sol es parte de la esfera de interacción identificado en las culturas andinas y tarapaqueñas.

La preferencia de contar con marcas estacionales en cambio de marcas calendáricas está documentada en las región andina aymara y quechua-hablantes. Las observaciones astronómicas establecidas con las cumbres de las montañas forman parte de todas las herramientas para pronosticar el ciclo de subsistencia.

\section{Agradecimientos}

Anthony Aveni, Karen Bassie, Christopher Clarkson, Ronald Dorn, Hal Green, Ximena Loayza, Brad Russell, Vesna Milosevic-Zdjelar, Any Valentín, Daniela Valenzuela, Oscar Varela, Alexi Vranich. Agradecemos a los comentaristas en el XIX Congreso Internacional de Arqueología Chilena, octubre 2012, donde hemos presentado originalmente este estudio.

\section{Referencias Citadas}

Aldunate, C. y V. Castro

1981 Las Chullpas de Toconce y su relación con el poblamiento altiplánico en el Loa Superior Período Tardío. Tesis doctoral, Universidad de Chile, Santiago.

Arbino, D. y M. Arnold

2012 Conquests of the Imagination: the Manipulation of Myth in Iberian Conquest Literatures. Nomenclatura: Aproximaciones a los Estudios Hispánicos, Primavera 1-26.

Arguedas, J.

1956 Puquio, una cultura en proceso de cambio. Revista del Museo Nacional de Historia 25:184-232.

Aveni, A.F.

1972 Astronomical Tables Intended for Use in Astroarchaeological Studies. American Antiquity 37(4):531-540.
Aveni, A.F.

1980 Skywatchers of Ancient Mexico. University of Texas Press, Austin.

Aveni, A.F.

1981 Horizon Astronomy in Incaic Cuzco. En Archaeoastronomy in the Americas, editado por R. Williamson, pp. 305-318. Ballena Press, Los Altos, EEUU.

Aveni, A.F.

1992 On Seeing the Light: A Reply to Here Comes the Sun by Dearborn and Schreiber. Archaeoastronomy 10:22-24.

Aveni, A.F.

1996 Astronomy and the Ceque system. Journal of the Steward Anthropological Society 24(1,2):157-172.

Aveni, A.F.

1997 Stairways To the Stars: Skywatching in Three Great Ancient Cultures. John Wiley and Sons, Toronto. 
Aveni, A.F.

2008 Foundations of New World Cultural Astronomy. University Press of Colorado.

Bastien, J.

1978 Mountain of the Condor. West Publishing Co., New York.

Bauer, B.S.

1998 The Sacred Landscape of the Inca: the Cuzco Ceque System. University of Texas Press, Austin.

Bauer B. S. y D.S.P. Dearborn

1995 Astronomy and Empire in the Ancient Andes: The Cultural Origins of Inca Sky Watching. University of Texas Press, Austin.

Berenguer, J.

1994 Asentamientos, caravaneros y tráfico de larga distancia en el Norte de Chile: el caso de Santa Bárbara. En De Costa a Selva, editado por M.E. Albeck, pp. 17-50. Instituto Interdisciplinario Tilcara.

Berenguer, J. y P. Dauelsberg

19891 Norte Grande en la órbita de Tiwanaku (400 a 1.200 d.C). En Culturas de Chile: prehistoria desde sus orígenes hasta los albores de la conquista, editado por J. Hidalgo, V. Schiappacasse, H. Niemmeyer, C. Aldunate, e I. Solimano, pp. 129-180. Editorial Andrés Bello, Santiago.

Bittman, B.

1985 Reflections on Geoglyphs from Northern Chile. Latin American Studies 1, Rickmansworth, Inglaterra.

Briones, L.

2006 The Geoglyphs of the Northern Chilean Desert: An Archaeological and Artistic Perspective. Antiquity 80:9-24.

Briones, L., A. Díaz, C. Mondaca, y P. Clarkson

1999 Huasquiña, las chacras y los geoglifos del desierto: una aproximación al arte rupestre andino. Diálogo Andino 18:39-61.

Briones, L. y J. Chacama

1987 Arte Rupestre de Ariquilda: análisis descriptivo de un sitio con geoglifos y su vinculación con la prehistoria regional. Chungara 18:15-66.

Chacama, J. y G. Espinosa

1997 La ruta tarapacá: análisis de un mito y una imagen rupestre en el norte de Chile. Actas del XIV Congreso de Arqueología Chilena 2:769-792. Museo Regional de Atacama, Copiapó.

Clarkson, P.B. y L. Briones

2001 Geoglifos, senderos y etnoarqueología de caravanas en el desierto chileno. Boletín Museo Chileno de Arte Precolombino 8:35-45.

Dearborn, D.S.P. y K.J. Schreiber

1987 Here Comes the Sun: the Cuzco-Machu Picchu Connection. Archaeoastronomy 9:15-37.

Díaz, A. y C. Mondaca

1999 Geografía y geoglifos de la pampa de Tamarugal, antecedentes sobre geografía cultural y el arte rupestre andino. Seminario para optar al título de Profesor en Historia y Geografía. Universidad de Tarapacá, Arica.

Gavilán, V. y A.M. Carrasco

2009 Festividades andinas y religiosidad en el norte chileno. Chungara 41(1):101-112.

Hawkins, G.

1964 Stonehenge: a Neolithic computer. Nature 202:1258-1261.
Isbell, B. J.

1982 Culture Confronts Nature in the Dialectical World of the Tropics. En Ethnoastronomy and Archaeoastronomy in the American Tropics, editado por A. Aveni y G. Urton. Annals of the New York Academy of Sciences 385:353-363.

Mishkin, B.

1940 Cosmological ideas among the Indians of the southern Andes. Journal of American Folklore 53:225-241.

Mishkin, B.

1946 The Contemporary Quechua. Handbook of South American Indians 2: 441-470. Smithsonian Institution, Washington, D.C.

Muñoz, I.

1989 El período formativo en el norte grande (1000 a.C. a 500 a.C.). En Culturas de Chile: prehistoria desde sus orígenes hasta los albores de la conquista, editado por $\mathrm{J}$. Hidalgo, V. Schiappacasse, H. Niemmeyer, C. Aldunate, e I. Solimano, pp. 107-128. Editorial Andrés Bello, Santiago.

Nielsen, A.E.

1997-8 Tráfico de caravanas en el sur de Bolivia: observaciones etnográficas e implicancias arqueológicas. Relaciones de la Sociedad Argentina de Antropología XXII-XXIII:139-179.

Nielsen, A.E.

1997 El tráfico caravanero visto desde La Jara. Estudios Atacameños 14:339-371.

Núñez, L.

1976 Geoglifos y tráfico de caravanas en el desierto chileno. In Homenaje al Dr. Gustavo le Paige, s.j., Anales de la Universidad del Norte (Chile) 10:147-201.

Núñez, L.

1985 Petroglifos y tráfico en el desierto chileno. Estudios en Arte Rupestre, pp. 243-263. Museo Chileno de Arte Precolombino, Santiago.

Núñez, L. y L. Briones

1967-8 Petroglifos del sitio Tarapacá-47. Estudios Arqueológicos 3-4:43-84. Universidad de Chile, Antofagasta.

Núñez, L. y T.S. Dillehay

1995 Movilidad giratoria, armonía social y desarrollo en los Andes Meridionales: patrones de tráfico e interacción económica. Universidad Católica del Norte, segunda edición.

Núñez del Prado, J.

1970 El mundo sobrenatural de los quechuas del sur del Perú a través de la comunidad de Qotobamba. Allpanchis 2:57-119.

Orlove, B.S.

1979 Two Rituals and Three Hypotheses: An Examination of Solstice Divination in Southern Highland Peru. Anthropological Quarterly 52:86-98.

Orlove, B., J.C.H. Change, y M.A. Cane

2000 Forecasting Andean Rainfall and Crop Yield from the Influence of El Niño on Pleiades Visibility. Letters, Nature 402: 68-71.

Pimentel, G.

2009 Las huacas del tráfico, arquitectura ceremonial en rutas prehispánicas del desierto de Atacama. Boletín del Museo Chileno de Arte Precolombino 14(2):9-38.

Reinhard, J.

1985 Sacred Mountains: An Ethno-archaeological Study of High Andean Ruins. Mountain Research and Development 5(4):299-317. 
Reinhard, Johan

2002 A High Altitude Archaeological Survey in Northern Chile. Chungara 34(1):85-99.

Reinhard, J. y J. Sanhueza

1982 Expedición arqueológica al altiplano de Tarapacá y sus cumbres. Revista de la Corporación para el Desarrollo de la Ciencia 2(2): 17-42. Santiago.

Rivera, M.A.

1991 Prehistory of Northern Chile: A Synthesis. Journal of World Prehistory 5(1):1-47.

Romero, A.

1996 Enfrentamientos rituales en la cultura Arica: interpretación de un ícono rupestre. Chungara 28(1-2):115-132.

Ruggles, C.L.N. y N.J. Saunders

1993 The Study of Cultural Astronomy. En Astronomies and Cultures: Papers derived from the third "Oxford" International Symposium on Archaeoastronomy, editado por C. Ruggles y N. Saunders, pp. 1-31. University Press of Colorado.

Sepúlveda, M.A., Á.L. Romero, y L. Briones

2005 Tráfico de caravanas, arte rupestre y ritualidad en la quebrada de Suca (extremo norte de Chile). Chungara 37 (2):225-243.

Sinclaire, C.

1994 Los sitios de "muros y cajas" del río Loa y su relación con el tráfico de caravanas. En De Costa a Selva, editado por M.E. Albeck, pp. 51-76. Instituto Interdisciplinario Tilcara.

Tello, J. y P. Miranda

1923 Wallallo: Ceremonias gentilicias realizadas en la región Cisandina del Perú central (Distrito Arqueológico de Casta). Inca 1(2):475-549.

Thom, A.

1967 Megalithic sites in Britain. Oxford University Press, Oxford.

Thom, A.

1971 Megalithic lunar observatories. Oxford University Press, Oxford.

Tudela, $\mathrm{P}$.

2000 La religión tradicional entre los aymaras de Arica. Revista Chilena de Antropología 15:99-118.

Urton, G.

1981a Animals and Astronomy in the Quechua Universe. Proceedings of the American Philosophical Society 125(2):110-127.

Nota

1 Está incluido: precesión de los equinoccios, 2) la deviación del horizonte observado y el horizonte astronómico, 3) la refracción atmosférica, 4) la extinción atmosférica, 5) las
Urton, G.

1981b At the Crossroads of the Earth and the Sky: An Andean Cosmology. University of Texas Press, Austin.

Urton, G.

1983 El sistema de orientaciones de los incas y de algunos quechuahablantes actuales tal como queda reflejado en su concepto de la astronomía y del universo. Revista Anthropológica 1(1):209-238.

van Kessel, J.

1976 La pictografía rupestre como imagen votiva: un intento de interpretación antropológica. In Homenaje al Dr. Gustavo le Paige, s.j., Anales de la Universidad del Norte 10:227-244.

van Kessel, J.

2001 Se busca: un dios para un desarrollo con identidad. Revista de Ciencias Sociales 11:84-98. Universidad de Arturo Prat, Iquique.

van Kessel, J.

2006 Economía bidimensional andina. Revista de Ciencias Sociales 17:86-106. Universidad de Arturo Prat, Iquique.

van Kessel, J. y P.E. Salas

2002 Señas y señaleros de la Santa Tierra: Agronomía Andina. Wageningen studies on heterogeneity and relocalization No.4, Departamento de Sociología Rural de la Universidad de Wageningen, Holanda.

Vitry, C.

2007 Caminos rituales y montañas sagradas: estudio de la vialidad inka en el nevado de Chañi, Argentina. Boletín del Museo Chileno de Arte Precolombino 12(2):69-84.

Vranich, A.

2006 The Construction and Reconstruction of Ritual Space at Tiwanaku, Bolivia (A.D. 500-1000). Journal of Field Archaeology 3:121-136.

Yampara, S.

1992 Economía comunitaria aymara. En La Cosmovisión Aymara, editado por van den Berg, H, y Norbert Schiffers, pp. 143-186. UCG/HISBOL, La Paz.

Zuidema, R. T.

1962 The Ceque System of Cuzco: the Social Organization of the Capital of the Inca. E.J. Brill, Leiden.

Zuidema, R.T.

1981 The Inca Observations in Cuzco of the Solar and Lunar Passages Through Zenith and Antizenith. En Archaeoastronomy in the Americas, editado por R Williamson, pp. 319-342. Ballena Press, Santa Barbara.

variaciones de elevación barométrica y 5) los cuatro casos de salida y puesta heliacal (Aveni, 1972:532, 539). 
